\title{
INFLUENCE OF HARVESTING TIME ON CHEMICAL COMPOSITION OF THE ESSENTIAL OIL OF ABIES KOREANA TWIGS
}

\author{
MIN SE0 ${ }^{1}$, KANDHASAMY SOWNDHARARAJAN ${ }^{1}$, SONGMUN KIM1,2,* \\ ${ }^{1}$ Department of Biological Environment, Kangwon National University, Chuncheon 24341, Gangwon-do, Republic of Korea, ${ }^{2}$ Gangwon \\ Perfume Alchemy Co., Ltd., Chuncheon 24341, Gangwon-do, Republic of Korea \\ Email: perfume@kangwon.ac.kr \\ Received: 05 Sep 2016 Revised and Accepted: 15 Oct 2016
}

\begin{abstract}
Objective: In the present study, the influence of harvesting time (April, June, August and October 2015) on the essential oil composition of Abies koreana twigs from Korea was investigated.

Methods: The essential oil from the twigs of $A$. koreana was isolated by steam distillation and its chemical composition was determined by gas chromatography-mass spectrometry (GC-MS).

Results: The essential oil yield was found to vary from 0.76 to $1.20 \%$ depending on the month of harvesting. The GC-MS analysis revealed the identification of 26 different essential oil components from the twigs harvested in the months of April, June, August and October, which were mostly monoterpene hydrocarbons (57.63-72.38\%) followed by oxygenated monoterpenes (18.82-25.96\%). Harvesting time mainly influenced on the concentration of the major components of the essential oil from the twigs of $A$. koreana. Limonene (17.38-31.13\%), bornyl acetate (13.22-21.17\%), camphene (12.56-13.26\%), $\alpha$-pinene (11.05-13.02\%), $\beta$-pinene (4.55-5.70\%), 3-carene (5.21-6.43\%) and $\beta$-eudesmol (1.49-8.24\%) were detected as the major components in the essential oil.
\end{abstract}

Conclusion: The main differences between the essential oil compositions of four different months can be referred to limonene and bornyl acetate. The results showed considerable variations in the composition of essential oil, particularly quantitative variation during different harvesting months.

Keywords: Abies koreana, Essential oil, Harvesting time, Seasonal, Twigs

(C) 2016 The Authors. Published by Innovare Academic Sciences Pvt Ltd. This is an open access article under the CC BY license (http://creativecommons.org/licenses/by/4. 0/] DOI: http://dx.doi.org/10.22159/ijpps.2016v8i12.15056

\section{INTRODUCTION}

The genus Abies (Pinaceae) consists of 51 species of coniferous evergreen trees and is widely distributed in temperate and boreal regions of the northern hemisphere, mainly in mountainous regions [1]. Several species of Abies are used in the traditional medicine to treat various disorders including colds, stomachache, indigestion and pulmonary diseases [2]. Among them, Abies koreana Wilson (Korean fir; Korean name: Kusang namu) is a slow growing shrub or broadly pyramidal evergreen tree and distributed in the alpine regions of Republic of Korea [3]. The needles of this plant are used commercially in the cosmetic and fragrance industries to whiten the skin and to treat atopic dermatitis and asthma. The essential oil from the needles also provides an UV protection effect by inhibiting the melanin synthesis in cells [4]. Kim et al. [5-7] reported the presence of lignans and triterpenoids (secocycloartenoid and two lanostane-type) in this plant. In addition, the supercritical carbon dioxide extract from the needles of A. koreana exhibited memory enhancing effect in mice [8]. Previously, some authors reported the essential oil composition and its antimicrobial activity of $A$. koreana of different origins [2, 3, 9, 10]. However, the published data about the essential oil composition of $A$. koreana has been extensively varied between the authors.

The essential oils are mainly composed of terpenes and their oxygenated derivatives including alcohols, aldehydes, ketones, acids, esters, etc. The complex mixtures of essential oil components provide a characteristic aroma to plant foliage [11]. In general, the yield and chemical composition of the essential oil producing plants have been greatly associated with the environmental parameters such as temperature, relative humidity, sunlight, harvesting season and soil properties as well as the maturity of the plant and its physiological and biosynthetic pathway [12-16]. Among them, the season and duration of sunlight may influence the chemistry of the plant, since many components may be stored at a specific period to respond to environmental changes [17]. In addition, the biological activity of the essential oil is mainly correlated with its chemical composition. A number of studies have been reported previously in relation to seasonal influences in the yield and chemical composition of essential oils from various plant species and showed great variations in the concentration of essential oil components [12, 17-19]

The study of the influence of seasonal variation on the essential oil composition of $A$. koreana twigs is required to increase the quality and quantity of essential oil production. Further, there have been no reports on seasonal variation in the essential oil composition of $A$. koreana twigs. With regard to this topic, the present study was carried out to determine the chemical composition of the essential oil of Korean A. koreana twigs collected at different months.

\section{MATERIALS AND METHODS}

\section{Plant material}

The twigs of $A$. koreana were collected from Inje, Gangwon-do, Republic of Korea during the last week of April, June, August and October 2015. The plant was authenticated and deposited in the Herbarium, Daejin University, Pocheon, Gyeonggi-do, Republic of Korea with voucher number DJU-20152382.

\section{Extraction of essential oil}

The essential oil from the twigs of A. koreana harvested over different months was extracted by steam distillation (Hanil LabTech. Republic of Korea) using a Clevenger-type apparatus for $90 \mathrm{~min}$ at $100{ }^{\circ} \mathrm{C}$. The steam distillation was carried out with $1 \mathrm{~kg}$ of fresh $A$. koreana twigs. The essential oil extraction was performed immediately after harvesting the plant material. The essential oil yield $(\%, v / w)$ was calculated in triplicate on a fresh weight basis. The extracted essential oil was dried by using anhydrous sodium sulfate and was then stored at $4{ }^{\circ} \mathrm{C}$ until further analysis.

\section{Gas chromatography-mass spectrometry (GC-MS) analysis}

GC-MS analysis was performed with a Varian CP 3800 gas chromatography equipped with a VF-5 MS polydimethylsiloxane 
capillary column $(30 \mathrm{~m} \times 0.25 \mathrm{~mm} \times 0.25 \mu \mathrm{m})$ and a Varian $1200 \mathrm{~L}$ mass detector (Varian, CA, USA). Helium was used as a carrier gas at the rate of $1 \mathrm{ml} / \mathrm{min}$. Oven temperature was kept at $50{ }^{\circ} \mathrm{C}$ for $5 \mathrm{~min}$ initially and then raised with the rate of $5{ }^{\circ} \mathrm{C} / \mathrm{min}$ to $250{ }^{\circ} \mathrm{C} / \mathrm{min}$. The injected volume of essential oil was $10 \mu \mathrm{l}$ with a split ratio of 1:10. The injector temperature was set at $250^{\circ} \mathrm{C}$. The mass spectra were recorded in the electrospray ionization mode at $70 \mathrm{eV}$ in a scan range of $50-600 \mathrm{~m} / \mathrm{z}$.

\section{Identification of essential oil constituents}

The components of essential oils were identified by comparing the retention indices of the GC peaks obtained using homologous series of $n$-alkanes $\left(C_{8}-C_{20}\right)$ with those reported in the literature [20]. The mass spectra of the peaks were also matched with standards reported in the literature and National Institute of Standards and Technology (NIST, 3.0) library. The relative amount of individual component was calculated based on the GC peak area.

\section{RESULTS AND DISCUSSION}

The essential oil obtained from the twigs of A. koreana was pale yellow in color with an intensely coniferous, green and woody aroma. The essential oil yield from the twigs of A. koreana ranged from $0.76 \%$ to $1.20 \%$ during the different harvesting times. The essential oil yield varied with respective harvesting months (April, June, August and October) and the highest yield was obtained from a sample collected in the month of August $(1.20 \% \mathrm{v} / \mathrm{w})$. The qualitative and quantitative composition of the essential oil from the twigs of $A$. koreana at different harvesting times is presented in table 1. Altogether, 26 volatile components, forming $98.35-98.59 \%$ of the total oil compositions were identified from the essential oil samples of four different months (In April-23, June-22, August-25, and October-22 components) based on the retention indices and mass spectral data. Among them, 20 components were detected in all the four essential oil samples. The components are listed in order of their elution from a VF-5MS column. The essential oil samples mainly contain monoterpene hydrocarbons (57.63-72.38\%) followed by oxygenated monoterpenes (18.82-25.96\%), oxygenated sesquiterpenes $(2.84-12.2 \%)$ and sesquiterpene hydrocarbons $(1.1-$ $2.55 \%$ ) (fig. 1). It was observed that the presence of the highest percentage of monoterpene hydrocarbons in the sample collected in the month of August (72.38\%) and the lowest percentage in the month of April (57.63\%). The content of monoterpene hydrocarbons increased from April (57.63\%) to August (72.38\%) and decreased in October (66.65\%). The opposite pattern was observed in relation to oxygenated mono-and-sesquiterpenes.

Table 1: Influence of harvesting time on the chemical composition of essential oil from the twigs of Abies koreana

\begin{tabular}{|c|c|c|c|c|c|c|c|}
\hline \multirow[t]{2}{*}{ S. No. } & \multirow[t]{2}{*}{ Component } & \multirow[t]{2}{*}{$\mathbf{R} \mathbf{I}^{\mathbf{a}}$} & \multirow[t]{2}{*}{$\mathbf{R I}^{\mathbf{b}}$} & \multicolumn{4}{|l|}{ Area (\%) } \\
\hline & & & & April & June & August & October \\
\hline 1 & Santene & 888 & 902 & $1.75 \pm 0.18$ & $1.60 \pm 0.46$ & $1.76 \pm 0.12$ & $1.55 \pm 0.31$ \\
\hline 2 & Tricyclene & 926 & 934 & $1.91 \pm 0.28$ & $2.66 \pm 0.76$ & $1.91 \pm 0.16$ & $1.88 \pm 0.09$ \\
\hline 3 & $\alpha$-Pinene & 939 & 946 & $12.92 \pm 0.30$ & $12.77 \pm 0.84$ & $11.05 \pm 0.18$ & $13.02 \pm 0.90$ \\
\hline 4 & Camphene & 954 & 959 & $13.09 \pm 0.43$ & $13.26 \pm 0.42$ & $12.69 \pm 0.45$ & $12.56 \pm 0.24$ \\
\hline 5 & $\beta$-Pinene & 979 & 980 & $5.67 \pm 0.65$ & $5.70 \pm 0.68$ & $4.55 \pm 0.20$ & $5.16 \pm 0.13$ \\
\hline 6 & 3-Carene & 1011 & 1013 & $5.75 \pm 0.05$ & $6.27 \pm 0.32$ & $6.43 \pm 0.29$ & $5.21 \pm 0.09$ \\
\hline 7 & Limonene & 1021 & 1018 & $17.38 \pm 0.47$ & $25.91 \pm 0.56$ & $31.13 \pm 0.88$ & $28.02 \pm 1.06$ \\
\hline 8 & $\gamma$-Terpinene & 1059 & 1064 & $0.15 \pm 0.01$ & $0.24 \pm 0.01$ & $0.20 \pm 0.03$ & - \\
\hline 9 & Terpinolene & 1088 & 1084 & $0.77 \pm 0.10$ & $1.03 \pm 0.02$ & $0.87 \pm 0.08$ & $0.80 \pm 0.04$ \\
\hline 10 & Borneol & 1169 & 1165 & $0.27 \pm 0.02$ & $1.47 \pm 0.22$ & $4.43 \pm 0.28$ & $1.09 \pm 0.19$ \\
\hline 11 & Linalyl formate & 1216 & 1218 & $0.31 \pm 0.04$ & $0.28 \pm 0.14$ & $0.77 \pm 0.03$ & $0.69 \pm 0.13$ \\
\hline 12 & $\beta$-Fenchyl acetate & 1232 & 1234 & $2.47 \pm 0.17$ & $2.95 \pm 0.77$ & $2.00 \pm 0.05$ & $3.08 \pm 0.13$ \\
\hline 13 & Bornyl acetate & 1285 & 1286 & $21.17 \pm 1.10$ & $17.59 \pm 0.26$ & $13.22 \pm 0.05$ & $17.13 \pm 0.35$ \\
\hline 14 & $\alpha$-Terpinyl acetate & 1349 & 1356 & $1.46 \pm 0.09$ & $1.31 \pm 0.02$ & $1.27 \pm 0.17$ & $1.72 \pm 0.22$ \\
\hline 15 & Geranyl acetate & 1365 & 1368 & $0.29 \pm 0.05$ & $0.38 \pm 0.17$ & $0.69 \pm 0.41$ & $0.21 \pm 0.04$ \\
\hline 16 & Caryophyllene & 1419 & 1412 & $0.25 \pm 0.08$ & $0.30 \pm 0.09$ & $0.38 \pm 0.20$ & $0.45 \pm 0.15$ \\
\hline 17 & $\alpha$-Humulene & 1454 & 1460 & $0.20 \pm 0.09$ & $0.25 \pm 0.02$ & $0.27 \pm 0.09$ & $0.20 \pm 0.04$ \\
\hline 18 & $\alpha$-Gurjunene & 1477 & 1481 & $0.22 \pm 0.02$ & $0.55 \pm 0.04$ & $0.75 \pm 0.45$ & $0.28 \pm 0.06$ \\
\hline 19 & $\gamma$-Muurolene & 1479 & 1484 & - & - & $0.28 \pm 0.06$ & - \\
\hline 20 & $\beta$-Selinene & 1490 & 1492 & $0.37 \pm 0.11$ & - & $0.24 \pm 0.03$ & $0.16 \pm 0.02$ \\
\hline 21 & $\alpha$-Farnesene & 1505 & 1509 & - & $0.86 \pm 0.21$ & $0.32 \pm 0.12$ & - \\
\hline 22 & $\beta$-Bisabolene & 1505 & 1510 & - & - & $0.31 \pm 0.05$ & - \\
\hline 23 & Nerolidol & 1563 & 1565 & $1.44 \pm 0.30$ & $0.39 \pm 0.03$ & $0.56 \pm 0.03$ & $0.27 \pm 0.06$ \\
\hline 24 & Selina-6-en-4-ol & 1624 & 1625 & $1.31 \pm 0.25$ & - & - & $0.30 \pm 0.04$ \\
\hline 25 & $\beta$-Eudesmol & 1650 & 1652 & $8.24 \pm 0.75$ & $1.51 \pm 0.14$ & $1.49 \pm 0.20$ & $4.14 \pm 0.42$ \\
\hline \multirow[t]{3}{*}{26} & $\alpha$-Bisabolol & 1685 & 1689 & $1.21 \pm 0.38$ & $1.12 \pm 0.33$ & $0.79 \pm 0.08$ & $0.55 \pm 0.23$ \\
\hline & Total identified & & & $98.59 \pm 0.27$ & $98.40 \pm 0.24$ & $98.35 \pm 0.59$ & $98.47 \pm 0.48$ \\
\hline & Oil yield (v/w) & & & $0.76 \pm 0.07$ & $1.11 \pm 0.08$ & $1.20 \pm 0.09$ & $1.00 \pm 0.02$ \\
\hline
\end{tabular}

$\mathrm{RI}^{\mathrm{a}}$-Comparison of retention indices with those reported in the literature (Adams, 2007), $\mathrm{RI}^{\mathrm{b}}$-Retention indices relative to $\mathrm{n}$-alkanes $\left(\mathrm{C}_{8}-\mathrm{C}_{20}\right)$ on the VF-5ms column, Values are mean of three replicate determinations $(n=3) \pm$ standard deviation.

Limonene (17.38-31.13\%), bornyl acetate (13.22-21.17\%), camphene $(12.56-13.26 \%), \alpha$-pinene $(11.05-13.02 \%), \beta$-pinene (4.55-5.70\%), 3-carene (5.21-6.43\%) and $\beta$-eudesmol (1.49$8.24 \%$ ) were registered as the major components of the essential oil. In addition, the essential oil contains an unsaturated terpene, santene (1.55-1.76\%). The results revealed considerable variations in the essential oil composition of A. koreana twigs, especially quantitative variation at different harvesting months. When compared to all the four essential oils, the main differences between samples were noticed especially on the level of a monoterpene hydrocarbon, limonene and an oxygenated monoterpene, bornyl acetate (fig. 2). The accumulation of limonene increased during the harvesting months from April $(17.38 \%)$ to August (31.13\%) and decreased in October (28.02\%). In contrast, the amount of bornyl acetate was decreased during the harvesting months from April (21.17\%) to August (13.22\%) and increased in October $(17.13 \%)$. The highest level of $\beta$-eudesmol content (8.24\%) was detected in the month of April. The variations in other components at different harvesting months were irregular (table 1). 


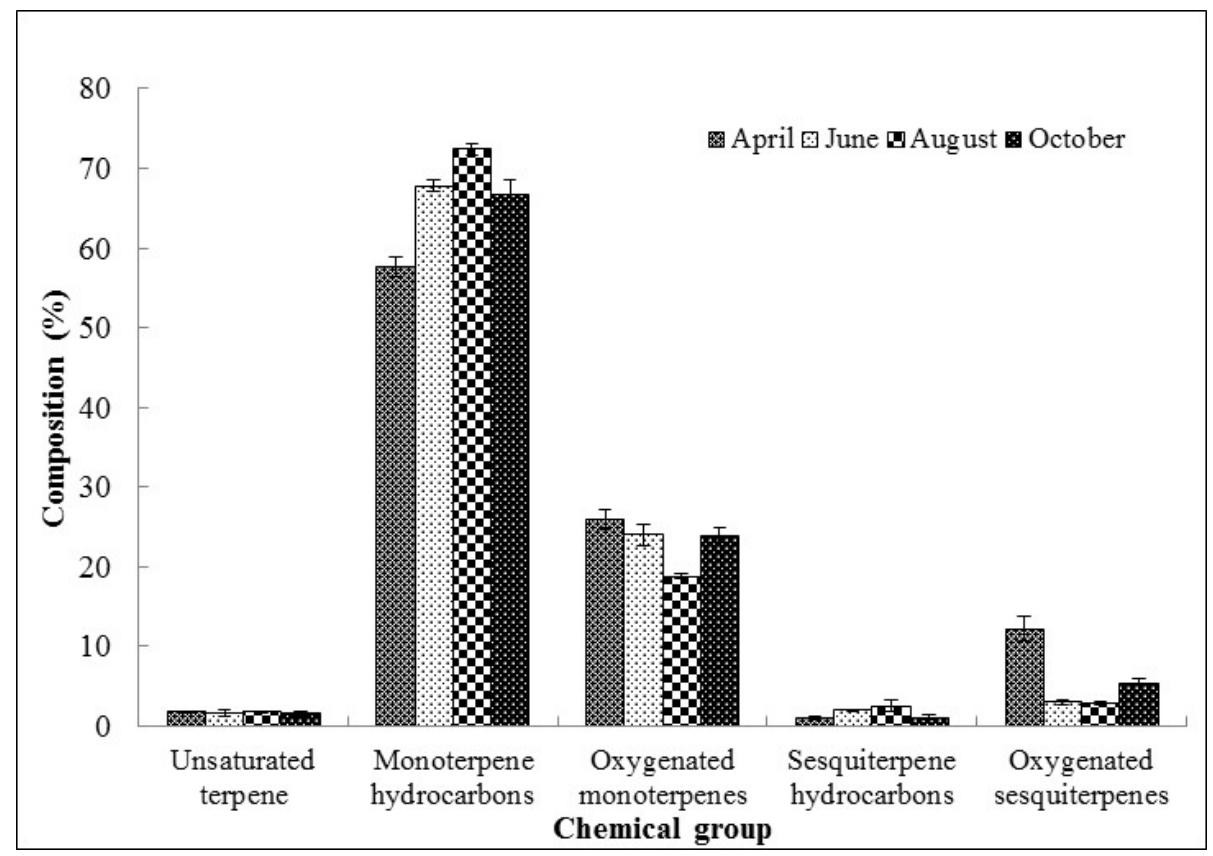

Fig. 1: Percentage concentration of different chemical groups in the essential oils from the twigs of Abies koreana collected at different months

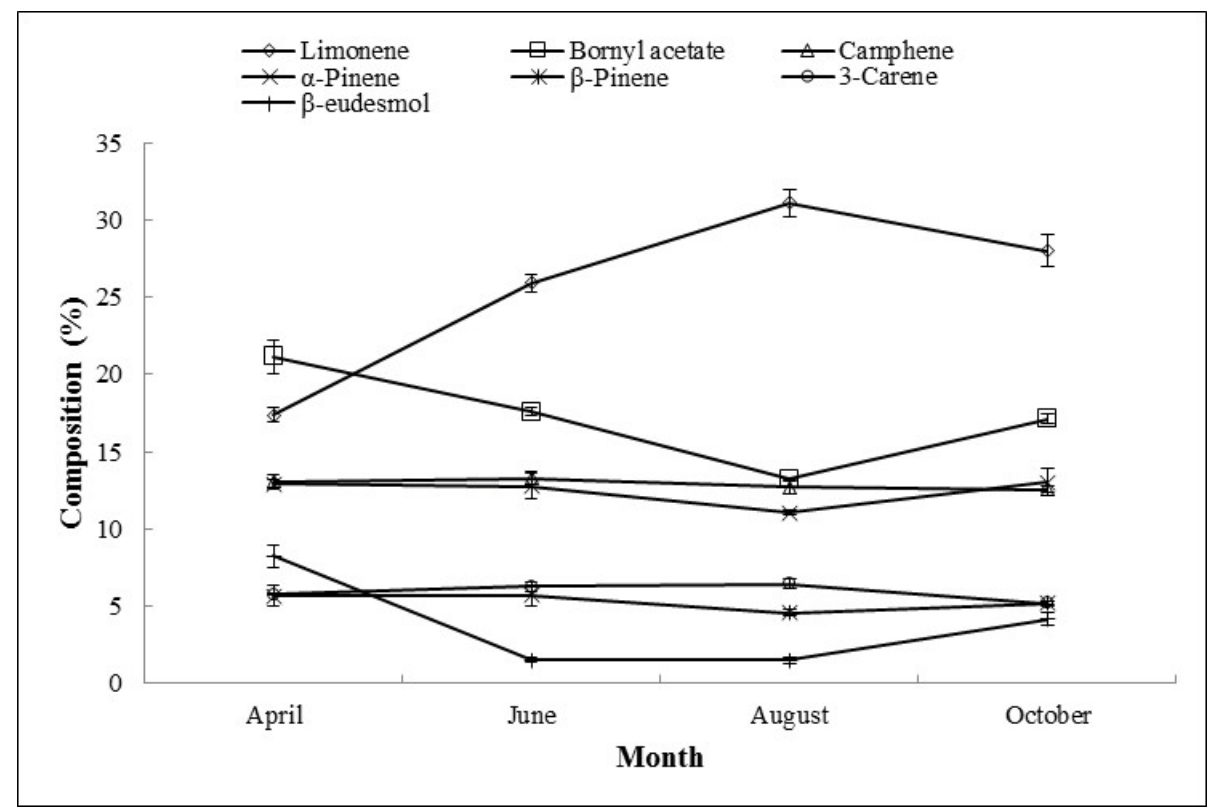

Fig. 2: Variation in the major components of the essential oils from the twigs of Abies koreana collected at different months

In the previous reports, the yields of essential oils from the needles, twigs and cones, as well as twigs with needles of $A$. koreana (by after $5 \mathrm{~h}$ of hydrodistillation) were $1.0 \%, 0.64 \%, 0.42 \%$ and $0.83 \%$, respectively [9]. In other studies, $0.6 \%, 0.53 \%$, and $0.9 \%$ of essential oil yields were obtained from the needles of A. koreana by Lee and Hong [2], Oh et al. [3] and Jeong et al. [10] respectively. In the present study, it was observed that the harvesting times highly influenced on the essential oil yield with the highest value in August $(1.20 \%)$ and the lowest value in April $(0.76 \%)$. The result showed that the yield was higher in the summer season than spring and autumn seasons. The variations in the essential oil yield of same species may be due to the time duration for distillation and collection time of plant materials. In this context, Rivoal et al. [21] also reported the terpene emission rate was significantly higher in spring and summer than in autumn and winter.
Previously, the essential oil compositions from the needles and twigs of $A$. koreana were reported by some authors. The chemical composition of $A$. koreana twigs from the present investigation is also in agreement with previous studies. The A. koreana essential oil contains complex mixture consisting mainly by monoterpene hydrocarbons (57.63-72.38\%). In conformity with the present findings, Oh et al. [3] reported that limonene (23.5\%), bornyl acetate (17.9\%), $\alpha$-pinene $(11.1 \%)$ and camphene $(10.2 \%)$ were the major components of essential oil from the needles of A. koreana. The results of the present study and previous studies show the high variation in the number of components in the essential oil of $A$. koreana. The concentration of major components such as limonene (8.58-23.5\%), bornyl acetate/bornyl ester (3.4-41.79\%), camphene $(10.2-22.5 \%), \alpha$-pinene $(6.07-23.2 \%)$ and $\beta$-pinene $(0.46-5.80 \%)$ were varied among the previously reported results $[2,3,9,10]$. 
Numerous authors have reported the variations in the chemical composition of essential oil due to the environmental conditions (climatic, seasonal and geographical), genetic differences, nutritional status of the plants, extraction methods and analytical techniques $[18,22-24]$. In addition, previous studies have reported that the essential oil composition of various medicinal and aromatic plants, when collected at different times varied significantly and the changes were mainly quantitative rather than qualitative $[17,18,25]$ The results revealed that the changes of essential oil content and composition of $A$. koreana twigs are possibly correlated with the various environmental factors commencing from different seasons.

\section{CONCLUSION}

Results of the present study clearly indicate the variations in the yield and composition of essential oils from different harvesting times. The major constituents of $A$. koreana essential oil such as limonene, bornyl acetate, camphene, $\alpha$-pinene, $\beta$-pinene, 3 -carene and $\beta$-eudesmol were considerably varied during the different harvesting times. According to the yield and concentration of monoterpene hydrocarbons, harvesting of $A$. koreana twigs during the summer season (June-August) was found to be the best. The findings of the present study could be useful for further commercial utilization of the essential oil of $A$. koreana twigs.

\section{ACKNOWLEDGEMENT}

This research was supported by the Ministry of Trade, Industry and Energy (MOTIE), Korea Institute for Advancement of Technology (KIAT) through the Encouragement Program for The Industries of Economic Cooperation Region (Project No. R0004940).

\section{CONFLICT OF INTERESTS}

We declare that we have no conflict of interest.

\section{REFERENCES}

1. Farjon A, Rushforth KD. A classification of Abies Miller (Pinaceae). Notes Roy Bot Garden Edinb 1989;46:9-79.

2. Lee JH, Hong SK. Comparative analysis of chemical compositions and antimicrobial activities of essential oils from Abies holophylla and Abies koreana. J Microbiol Biotechnol 2009;19:372-7.

3. Oh HJ, Ahn HM, So KH, Kim SS, Yun PY, Jeon GL, et al. Chemical and antimicrobial properties of essential oils from three coniferous trees Abies koreana, Cryptomeria japonica, and Torreya nucifera. J Appl Biol Chem 2007;50:164-9.

4. Wajs-Bonikowska A, Sienkiewicz M, Stobiecka A, Maciąg A, Szoka $Ł$, Karna E. Chemical composition and biological activity of Abies alba and A. koreana seed and cone essential oils and characterization of their seed hydrolates. Chem Biodiversity 2015;12:407-18.

5. Kim YG, Lee HJ, Ozawa SJ, Sasaya T, Moon CK. Lignans of Abies koreana Wilson. Mokuzai Gakkaishi 1994;40:414-8.

6. Kim HJ, Le QK, Lee MH, Kim TS, Lee HK, Kim YH, et al. A cytotoxic secocycloartenoid from Abies koreana. Arch Pharm Res 2001;24:527-31.

7. Kim HJ, Choi EH, Lee IS. Two lanostane triterpenoids from Abies koreana. Phytochemistry 2004;65:2545-9.

8. Kim K, Bu Y, Jeong S, Lim J, Kwon Y, Cha DS, et al. Memoryenhancing effect of a supercritical carbon dioxide fluid extract of the needles of Abies koreana on scopolamine-induced amnesia in mice. Biosci Biotechnol Biochem 2006;70:1821-6.

9. Baran S, von Reuss SH, König WA, Kalemba D. Composition of the essential oil of Abies koreana Wils. Flavour Fragrance J 2007;22:78-83.
10. Jeong SI, Lim JP, Jeon H. Chemical composition and antibacterial activities of the essential oil from Abies koreana. Phytother Res 2007;21:1246-50.

11. Fornari T, Vicente G, Vázquez E, García-Risco MR, Reglero G. Isolation of essential oil from different plants and herbs by supercritical fluid extraction. J Chromatogr A 2012;1250:34-48.

12. Gazim ZC, Amorim AC, Hovell AM, Rezende CM, Nascimento IA, Ferreira GA, et al. Seasonal variation, chemical composition, and analgesic and antimicrobial activities of the essential oil from leaves of Tetradenia riparia (Hochst.) Codd in Southern Brazil. Molecules 2010;15:5509-24.

13. Mangai SA, Subban R. Seasonal variation in the essential oil composition of Majorana hortensis moench from Western Ghats region of south India. Asian J Pharm Clin Res 2014;7:173-7.

14. Soni A, Dahiya P. Phytochemical analysis, antioxidant and antimicrobial activity of Syzygium caryophyllatum essential oil. Asian J Pharm Clin Res 2014;7 Suppl 2:202-5.

15. Jose B, Reddy LJ. Evaluation of antibacterial activity of the leaf and flower essential oils of Gliricidia sepium from south India. Int J Appl Pharm 2010;2:20-2.

16. Angel GR, Vimala B, Nambisan B. Antioxidant and antimicrobial activity of essential oils from nine starchy Curcuma species. Int J Curr Pharm Res 2012;4:45-7

17. Dhouiouia M, Boulila A, Chaabane H, Zina MS, Casabianca H. Seasonal changes in essential oil composition of Aristolochia longa L. ssp. paucinervis Batt. (Aristolochiaceae) roots and its antimicrobial activity. Ind Crops Prod 2016;83:301-6.

18. Ben Jemâa JM, Haouel S, Bouaziz M, Khouja ML. Seasonal variations in chemical composition and fumigant activity of five Eucalyptus essential oils against three moth pests of stored dates in Tunisia. J Stored Prod Res 2012;48:61-7.

19. Tyagi R, Sharma G, Jasuja ND, Menghan E. Indian medicinal plants as an effective antimicrobial agent. J Crit Rev 2016;3:69-71.

20. Adams RP. Identification of essential oil components by gas chromatography/mass spectrometry. 4th ed. Carol Stream (IL): Allured Publishing Co.; 2007.

21. Rivoal A, Fernandez C, Lavoir AV, Olivier R, Lecareux C, Greff S, et al. Environmental control of terpene emissions from Cistus monspeliensis L. in natural Mediterranean shrublands. Chemosphere 2010;78:942-9.

22. Mejri J, Abderrabba M, Mejri M. Chemical composition of the essential oil of Ruta chalepensis L: influence of drying, hydrodistillation duration and plant parts. Ind Crop Prod 2010;32:671-3.

23. Teixeira B, Marques A, Ramos C, Neng NR, Nogueira JMF, Saraiva JA, et al. Chemical composition and antibacterial and antioxidant properties of commercial essential oils. Ind Crop Prod 2013;43:587-95.

24. Rajabi Z, Ebrahimi M, Farajpour M, Mirza M, Ramshini H. Compositions and yield variation of essential oils among and within nine Salvia species from various areas of Iran. Ind Crop Prod 2014;61:233-9.

25. Kamatou GPP, Van Zyl RL, Van Vuuren SF, Figueiredo AC, Barroso JG, Pedro LG, et al. Seasonal variation in essential oil composition, oil toxicity and the biological activity of solvent extracts of three South African Salvia species. S Afr J Bot 2008;74:230-7.

\section{How to cite this article}

- Min Seo, Kandhasamy Sowndhararajan, Songmun Kim. Influence of harvesting time on the chemical composition of the essential oil of Abies koreana twigs. Int J Pharm Pharm Sci 2016;8(12):205-208. 